
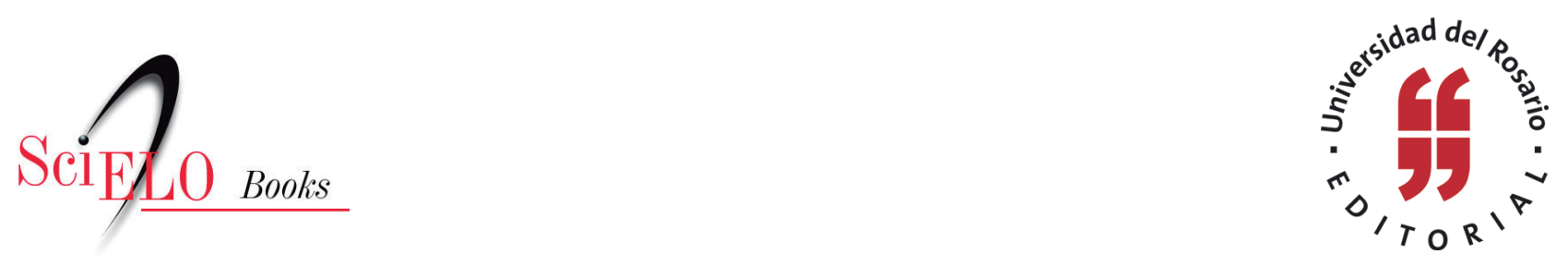

\title{
Derecho humano al agua en la comunidad wayúu bajo la figura matrilineal
}

\author{
Melanie Vangrieken Alvarado
}

VANGRIEKEN ALVARADO, M. Derecho humano al agua en la comunidad wayúu bajo la figura matrilineal. In: TORRES VILLARREAL, M.L., and IREGUI PARRA, P.M., ed. Discusiones contemporáneas sobre derechos humanos en el marco de la globalización [online]. Bogotá: Editorial Universidad del Rosario, 2015, pp. 35-61. ISBN: 978-958-738-671-4. https://doi.org/10.7476/9789587386714.0003.

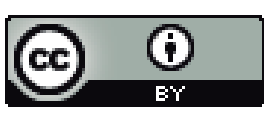

All the contents of this work, except where otherwise noted, is licensed under a Creative Commons Attribution 4.0 International license.

Todo o conteúdo deste trabalho, exceto quando houver ressalva, é publicado sob a licença Creative Commons Atribição $\underline{4.0}$.

Todo el contenido de esta obra, excepto donde se indique lo contrario, está bajo licencia de la licencia Creative Commons Reconocimento 4.0. 


\section{Derecho humano al agua en la comunidad wayúu bajo la figura matrilineal*}

Melanie Vangrieken Alvarado**
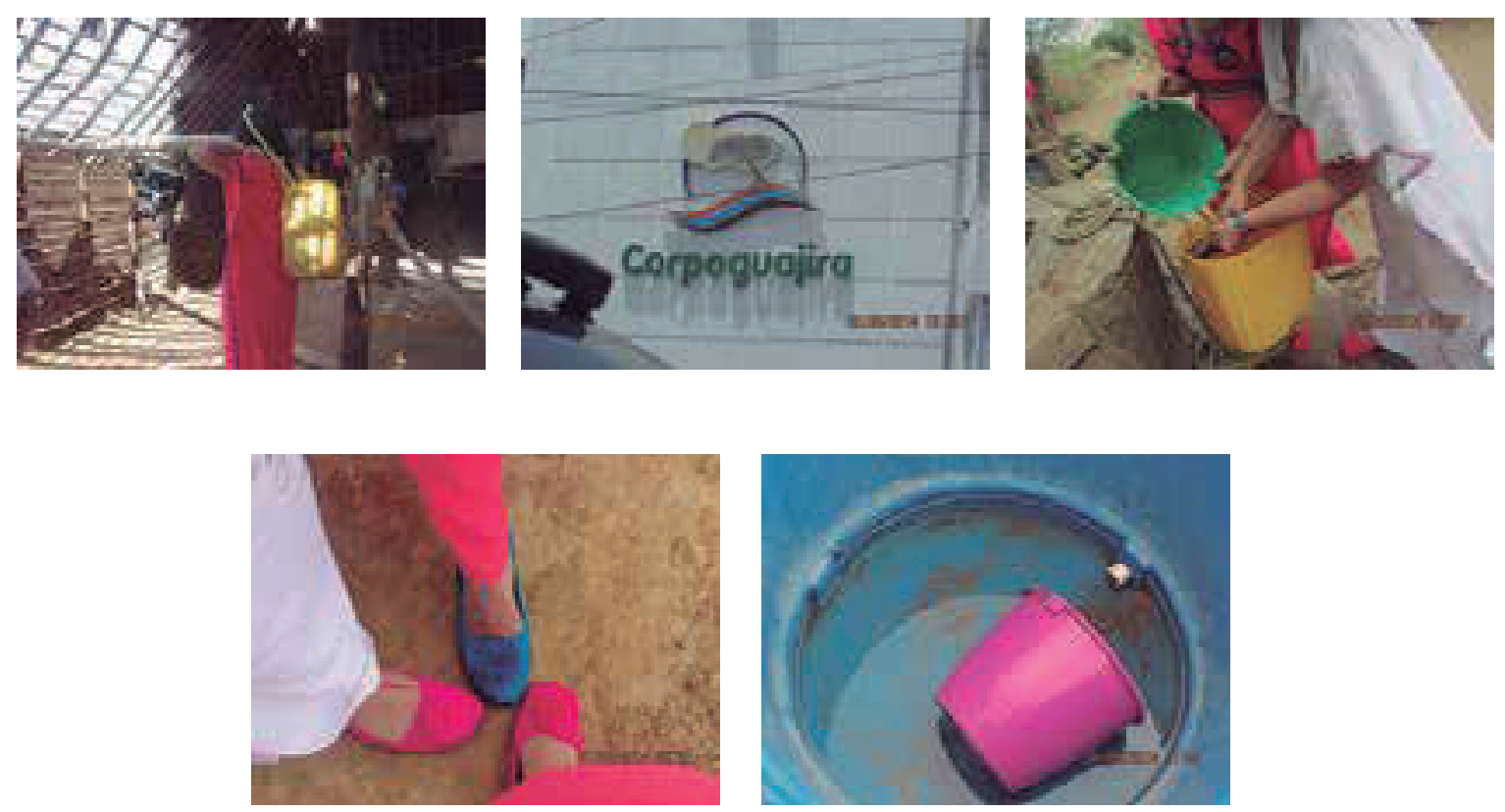

* Agradecimientos especiales a mi tutora Judith Echeverría Molina y a mis compañeras Carla Castellanos Gómez, Nataly De las Salas Castro y María Daniela Guzmán Gordon.

** Estudiante en formación en investigación, Universidad del Norte, División de Derecho, Ciencia Política y Relaciones Internacionales, Departamento de Derecho, V semestre, 2015. Correo electrónico: melanievangrieken@gmail.com. 


\section{Resumen}

A principios de mayo del 2014, en el afán de comprender un poco más de la cultura wayúu para poder llevar a cabo un nuevo proyecto de investigación que surgió en la Universidad del Norte, la literatura etnográfica - leída por primera vez en la obra de un poeta wayúu autor de "En las hondonadas maternas de la piel", Vito Apüshana, y otros autores como Estercilia Simanca y Miguel Angel Jusayu— ayudó a recrear el mundo indígena y conocer el concepto de agua desde su cosmovisión, y dio origen a esta investigación.

Lo más interesante es cómo el pueblo wayúu expresa a través de esta literatura la cotidianidad de la vida, pero acompañada de un elemento sagrado, y cómo a través de la observación cultiva la palabra, con una estética maravillosa donde el agua - o wuin en wayuunaiki- es un elemento fundamental de inspiración. Por un lado, está el mar Caribe, hacia el norte, y por el otro, el río Ranchería, uno de los escenarios más comunes en los escritos wayúus.

Otro aspecto fascinante de esta cultura consiste en un equilibrio armónico, donde el ser humano es apenas una parte, y no es el amo de la tierra. Se refiere a pensar que también hay un algo en las plantas, en los ríos, en toda la naturaleza que los convierte en deidades, como lo es juya, y resulta que según la creencia de los wayúus el río no es solo el agua que fluye, sino que además constituye un elemento sagrado que sostiene y conecta toda la vida, y de aquí nace un profundo respeto por ella.

Con el estudio sobre el pueblo wayúu, asentado en los terrenos ancestrales de la península de la Guajira al norte de Colombia, este escrito tiene como propósito presentar un análisis sobre el efecto que tiene el reconocimiento del derecho al agua como derecho humano en las condiciones de vida y la 
realización de los demás derechos humanos de las mujeres y niñas wayúus, como también en la noción jurídica fundamental del Estado para garantizar el acceso a sistemas de agua potable y al saneamiento de esta comunidad indígena.

Se parte de la recopilación de los pronunciamientos en materia del derecho humano al agua, el estudio de la importancia del tema en cuestión y un análisis de este derecho humano desde una perspectiva de género. Continuamos con la descripción de las condiciones de los sistemas de abastecimiento de agua en las comunidades wayúus y la identificación de las políticas públicas que existen en el departamento de la Guajira para garantizar el derecho humano al agua en estas comunidades, y posteriormente reconocemos las tradiciones, la cultura, el vocabulario, los conceptos y las necesidades de los asentamientos wayúus, por medio de la construcción del concepto de agua según las wayúus, además de la descripción del rol de las mujeres y niñas con respecto al abastecimiento de agua y sus acciones para hacer valer este derecho, con el fin de explicar cómo se les garantiza el derecho humano al agua a las mujeres y niñas wayúus.

\section{Introducción}

Desiertos llenos de encanto y embrujo, playas de carbón bordadas en blancas salinas y aguas cristalinas forman parte del paraíso guajiro, tierras exóticas orgullo de los paisajes colombianos; sin embargo, según la Organización de las Naciones Unidas (oNU), las condiciones de vida en el desierto se han visto deterioradas en los últimos años en el norte de Colombia. Las mujeres indígenas wayúus luchan para garantizar la supervivencia de su comunidad, a pesar de los cada vez más escasos recursos de agua.

En la Guajira, de acuerdo con el Plan de Manejo Ambiental de la Gobernación, las condiciones ambientales, caracterizadas 
por bajas precipitaciones anuales (por debajo de $500 \mathrm{~mm} / \mathrm{año}$ ), altos valores de evapotranspiración (generalmente superiores a $1500 \mathrm{~mm} / \mathrm{año}$ ) y bajas condiciones de humedad, generan escasez de agua, lo que se convierte en una de las mayores problemáticas para las comunidades indígenas wayúus, al ser el 20,5\% de la población indígena nacional (Departamento Nacional de Planeación [DNP], Instituto Colombiano de la Reforma Agraria [Incora], 1997) y el 48\% de la población de la Guajira, según el Censo General 2005, con una tasa de cobertura de acueductos de tan solo el 52\%.

Ante dicha situación, esta investigación promueve la idea del agua potable y el saneamiento como indispensables para la vida y la salud, y fundamentales para la dignidad de las comunidades wayúus, en especial para las mujeres y las niñas. Este apoyo se fundamenta en el reconocimiento del derecho humano al agua y al saneamiento de la Asamblea General de las Naciones Unidas, donde se sostiene que un agua potable limpia y el saneamiento son esenciales para la realización de todos los derechos humanos. Teniendo en cuenta ello, se exhorta al Estado y a las organizaciones internacionales a proporcionar recursos financieros, propiciar la capacitación y la transferencia de tecnología para ayudar a las comunidades indígenas wayúus, y proporcionar un suministro de agua potable y saneamiento saludable, limpio, accesible y asequible para todos.

Con los grandes avances en el reconocimiento del derecho al agua como derecho humano, este proyecto aborda las desigualdades que afectan a las mujeres y a las niñas en relación con los servicios de agua y saneamiento. Además, insta a resaltar la misión del Fondo de las Naciones Unidas para la Infancia (Unicef, por su acrónimo en inglés) y promover la igualdad de derechos de las mujeres y las niñas wayúus, 
quienes soportan la carga de ir por agua, como consecuencia de lo cual pierden oportunidades para la educación, para realizar actividades productivas y para el esparcimiento. Así, se apoya su participación plena en el desarrollo político, social y económico de sus comunidades.

Sin lugar a dudas, la concientización nacional sobre el esfuerzo que las mujeres y niñas de la comunidad wayúu hacen al realizar ciertas actividades para conseguir agua en pro de su comunidad, así como las condiciones en las que se encuentran los sistemas de abastecimiento de agua en los asentamientos wayúus, serán el incentivo perfecto para los proyectos sociales, participativos y sostenibles, encaminados a promover soluciones de abastecimiento de agua, saneamiento e higiene y gestión integral de fuentes hídricas:

El problema del agua va más allá de la cuestión del acceso. En muchos países, las niñas se ven obligadas a abandonar la escuela debido a la falta de instalaciones sanitarias, y las mujeres sufren violaciones y ataques cuando van por agua. (Ban Ki-moon, Secretario General de Naciones Unidas)

\section{Metodología}

Con el fin de determinar cómo se les garantiza el derecho humano al agua a las mujeres y niñas wayúus, se empleará la metodología cualitativa orientada a conclusiones, porque se está frente a una investigación que busca interpretar y comprender la realidad social circundante de la comunidad wayúu. Además, se busca estudiar la realidad en su contexto natural, tal como sucede, intentando obtener un sentido de, o interpretar, los fenómenos de acuerdo con los significados que tienen para las personas implicadas. Esta investigación 
cualitativa implica la utilización y recolección de una gran variedad de materiales que describen la rutina, las situaciones problemáticas y sus significados en la vida de las mujeres y niñas wayúus (Rodríguez et al., 1996).

Según la orientación del trabajo, se realizará un estudio de tipo descriptivo, con la finalidad de llegar a conocer las situaciones, costumbres y actitudes predominantes, a través de la descripción exacta de las actividades, objetos, procesos y personas dentro de la cultura wayúu, sin limitarse a la recolección de datos, sino abordando además la predicción e identificación de las relaciones que existen entre dos o más variables, incluyendo las implicaciones sociojurídicas del derecho humano al agua con esta cultura (Ávila, 2006).

Las técnicas empleadas para el logro de las metas definidas en los objetivos específicos de la investigación, están constituidas por la actividad participativa y la observación etnográfica en una ranchería ubicada en el centro-este del departamento de la Guajira, en el municipio de Maicao, con una población aproximada de veinticinco mujeres y niñas wayúus. Asimismo, la revisión de documentos oficiales como el Plan de Desarrollo Departamental 2012-2015 de la gobernación de la Guajira y entrevistas a funcionarios de entes relacionados con el tema, como lo es el subdirector de Corpoguajira. Además, entre las técnicas de investigación se incluyen las entrevistas semiestructuradas, la fotografía y el video, el grupo focal — como una técnica cualitativa para el estudio de las opiniones o actitudes de un grupo- y, por supuesto, la observación científica para describir los escenarios del estudio.

\section{Resultados}

Para abarcar el tema del derecho humano al agua en la comunidad wayúu bajo la figura matrilineal, es importante resaltar 
de dónde proviene el interés de esta investigación, así como los antecedentes de esta temática.

\section{Pronunciamientos sobre el derecho humano al agua}

E1 28 de julio de 2010, a través de la Resolución 64/292, la Asamblea General de las Naciones Unidas:

[...] reconoció explícitamente el derecho humano al agua y al saneamiento, reafirmando que un agua potable limpia y el saneamiento son esenciales para la realización de todos los derechos humanos. La Resolución exhorta a los Estados y organizaciones internacionales a proporcionar recursos financieros, a propiciar la capacitación y la transferencia de tecnología para ayudar a los países, en particular a los países en vías de desarrollo, a proporcionar un suministro de agua potable y saneamiento saludable, limpio, accesible y asequible para todos. (Departamento de Asuntos Económicos y Sociales de las Naciones Unidas, 2010)

En este mismo sentido, en noviembre del año 2002, el Comité de Derechos Económicos, Sociales y Culturales adoptó la Observación General no 15 sobre el derecho al agua, cuyo artículo 1.1 establece que "El derecho humano al agua es indispensable para una vida humana digna”. La Observación no 15 también define el derecho al agua como "el derecho de cada uno a disponer de agua suficiente, saludable, aceptable, físicamente accesible y asequible para su uso personal y doméstico". En el Congreso del año 2009, los sindicatos europeos de servicios públicos iniciaron la recaudación de firmas a favor del agua como un derecho humano. "El establecimiento de normas de Iniciativa Ciudadana Europea por parte de la Comisión Europea se dio en marzo del 2011" (Comisión Europea, 2014). 
Asimismo, la Corte Constitucional colombiana también se ha pronunciado con respecto a este tema, hecho evidenciado en las diferentes sentencias proferidas por este órgano. En primer lugar, cabe resaltar que desde el inicio de su jurisprudencia, ha considerado que "el derecho de toda persona al agua es un derecho fundamental, que es objeto de protección mediante acción de tutela en muchas de sus dimensiones"(Sentencia T-418 del 2010). De igual manera, la Sentencia T-740 del 2011 establece que el agua se instituye como una necesidad básica, al ser un elemento sólido para permitir la existencia del ser humano. En el ordenamiento jurídico colombiano, el agua posee un doble vínculo, ya que se erige como un derecho fundamental y como un servicio público. En este sentido, todas las personas tienen el derecho de acceder al servicio de acueducto en condiciones de calidad y cantidad suficiente, y por lo tanto el Estado está encargado de organizar, dirigir, garantizar y reglamentar su prestación.

La Sentencia T-312 del 2012 establece que la Corte ha definido el agua como un derecho fundamental, siempre que esté destinada al consumo de cada persona, argumentando para ello que el agua es un requisito necesario para poder efectuar otros derechos. A su vez, mediante la Sentencia T-232 de 1993 se determinó que el derecho al agua es un derecho fundamental para el hombre, por conexidad con los derechos fundamentales a la vida y la salud en cuanto al consumo humano como necesidad básica. La Sentencia T- 413 de 1995, por su parte, señaló que en cuanto el derecho al agua se refiere a la salud humana y a la salubridad pública, es un derecho fundamental. Igualmente, afirmó que es prioritario atender necesidades domésticas y garantizar agua potable para la familia. 
La doctrina también se ha pronunciado sobre este tema, con diversas opiniones:

El agua es una necesidad humana indispensable para la vida, esencial para vivir con dignidad. Sin agua no hay vida posible. Se trata de un derecho humano personalísimo, urbi et orbi, erga omnes, que debe ser acatado por cualquier sociedad y todo Estado. Resulta ser una condición esencial, previa, que condiciona la existencia y el ejercicio de cualquier otro derecho humano. (Iza y Aguilar, 2009)

La existencia de un derecho fundamental referente al agua, de acuerdo con la tendencia moderna, el derecho al agua concierne el aprovisionamiento de agua potable y al saneamiento. Este derecho implica tanto derechos como obligaciones para los ciudadanos y los poderes políticos. (Smtes, 2006)

\section{Importancia del derecho humano al agua}

El tema del derecho humano al agua es de gran interés, teniendo en cuenta que " $\mathrm{El}$ agua es vital para la supervivencia y la buena salud de todos los seres humanos. El derecho al agua implica el acceso al agua potable y a instalaciones sanitarias adecuadas" (Humaniun, 2009). Por consiguiente, el derecho al agua es fundamental e indispensable para concretar otros derechos humanos y/o fundamentales, como es el caso del derecho a la salud, y por ende el derecho a la vida, ya que estos no se pueden definir sin un acceso a sistemas de agua potable limpia y al saneamiento.

Por otra parte, el derecho al agua limpia y potable es un derecho esencial y trascendental porque el agua desempeña un papel fundamental en la vida diaria y en el entorno de 
cada ser humano. De tal manera, tiene múltiples funciones, entre ellas:

- La higiene: para la higiene personal (baños, lavado de manos, etc.) y para la higiene doméstica (loza, ropa, implementos de aseo, etc.).

- La hidratación: el agua que bebemos y que nuestro cuerpo necesita.

- El saneamiento adecuado: utilizada en ciertas instalaciones, como los baños que permiten la eliminación de orina y materia fecal.

- La conservación de la salud: nos permite hidratarnos y por tanto mantener activo nuestro organismo.

- La cocción: el agua utilizada para lavar y cocinar los alimentos.

- Cultivar la tierra: empleada para el crecimiento de las cosechas.

A su vez, el tema del derecho humano al agua es importante, considerando que el agua es "el elemento principal para el desarrollo de las personas y para todas las formas de vida" (Katmandú, 2003). Actualmente, este es un tema muy discutido ya que constituye un elemento fundamental, primordial, esencial y notable para que cada persona pueda tener una vida digna. Después de quince años de debates, la Asamblea General de Naciones Unidas aprobó la resolución que reconoce y determina al agua potable y al saneamiento como un derecho humano para el uso y goce de la vida y los demás derechos fundamentales y/o humanos. Dicha resolución fue aprobada por iniciativa de Bolivia, con votos favorables de 122 países - entre ellos Congo, Angola, Antigua y Barbuda, República Dominicana, Arabia Saudita, Bangladesh, Benín, Eritrea, 
Burundi, Congo, Cuba, Dominica, Ecuador, El Salvador, Fiji, Serbia, Georgia y Haití- y 44 votos en contra.

El derecho humano al agua no es un tema importante solo para países como los mencionados anteriormente, sino también para Colombia, dado que este derecho ha sido reconocido tácitamente en tratados e instrumentos internacionales ratificados por el país, como Convención sobre la eliminación de todas las formas de discriminación contra la mujer y la Convención de los Derechos del Niño. El derecho al agua potable y al saneamiento básico está respaldado en las disposiciones de la Constitución Política en la parte de los fines esenciales del Estado, en los derechos económicos, sociales y culturales y en los derechos colectivos y del ambiente (Defensoría del Pueblo, 2014).

\section{El derecho humano al agua desde una perspectiva de género}

La mujer y el hombre realizan diferentes actividades con respecto al abastecimiento del agua y los sistemas hidrológicos. En las culturas indígenas, las mujeres y las niñas son las encargadas del suministro, la gestión, la provisión y el abastecimiento del agua que necesitan la comunidad y la familia para la higiene, para alimentarse, para la conservación de la salud, para cultivar la tierra, entre otras actividades (Molinares y Echeverría, 2011). A causa de que las mujeres y las niñas de esta comunidad se encuentran en constante contacto con fuentes de agua no potable, están más expuestas a la contaminación, a enfermedades e incluso a abusos sexuales, ya que deben recorrer largas distancias para conseguir este recurso, entre arbustos, en el campo o sobre una montaña, lo que las pone en riesgo porque deben alejarse mucho para hacer sus necesidades y encontrar privacidad. El tiempo que las mujeres 
utilizan en la gestión, uso y provisión del agua a sus hogares implica una importante carga adicional para ellas, como también una reducción del tiempo disponible para la realización de otras actividades, como las relacionadas con la educación, la formación, la capacitación y la generación de iniciativas económicas o involucramiento en actividades remuneradas, así como su participación en actividades culturales, de recreación o de participación política con importantes implicaciones en la vida tanto privada como comunitaria (Ledo, 2005).

En relación con el tema de las mujeres y las niñas y el derecho humano al agua, en el año 2000 Tatiana Ordeñana Sierra desarrolló una investigación titulada Los derechos de las mujeres son derechos bumanos, que se ocupa de los derechos humanos y su declaración internacional, pero de igual manera abarca los derechos de las mujeres. En dicha investigación se hace un énfasis práctico en la declaración de los derechos humanos, la abolición de toda esclavitud y las libertades de los seres humanos. De igual manera, se hace referencia a la igualdad de género y, como necesidad básica para el progreso de la humanidad, que se elimine la discriminación, tal y como se declara en la proclamación de la Conferencia Internacional de Derechos humanos celebrada en Teherán en mayo de 1968, cuyo inciso 15 reza: "La discriminación de que sigue siendo aún víctima la mujer en distintas regiones del mundo debe ser eliminada" (Bernales-Ballesteros, 1996).

Hoy en día la mujer wayúu desempeña los roles más importantes dentro de su comunidad, lo que demuestra Carlos A. Pulgarín (1997) en su artículo "La mujer Wayuu", publicado en el diario El Tiempo, donde se explica que en la cultura wayúu la mujer desempeña un papel fundamental y esencial, hecho evidenciado en que cuando nace una niña,los miembros 
de la comunidad consideran que ello es una bendición de los grandes dioses.

\section{Condiciones de los sistemas de abastecimiento} de agua en las comunidades wayúus

Para las comunidades wayúus el abastecimiento de agua es uno de los principales obstáculos, debido a las desfavorables condiciones ambientales de la Guajira caracterizadas por las bajas precipitaciones, donde el agua subterránea es la única fuente permanente de abastecimiento. Por lo tanto, la carencia de corrientes hídricas y unas precipitaciones anuales por debajo de los $500 \mathrm{~mm}$ hacen que gran parte de los sistemas de abastecimiento giren en torno a la provisión de agua del subsuelo.

A lo largo del tiempo los wayúus han tenido que hacer grandes recorridos para lograr el aprovisionamiento del agua, actividad realizada principalmente por mujeres y niñas, en la cual invierten diariamente una considerable cantidad de tiempo y fuerza laboral, lo cual limita la realización de otros derechos humanos como la educación. Aun hoy el acarreo se realiza en burros - en las zonas donde todavía están disponibles-, bicicletas, carretas, vehículos, o por lo general a pie cuando las fuentes son cercanas, a menos de 250 metros (Benavídez, 2009).

La escasez de sistemas adecuados de abastecimiento de agua y saneamiento implica que para el 100\% de la población el principal sistema de suministro de agua sea el acarreo y la utilización de aguas lluvias. Se capta agua de diversas fuentes, tales como río, manantial, jagüey, albercas, agua de carrotanques que traen desde los principales municipios, agua subterránea movida por molinos y grandes reservorios. Según el contrato de consultoría no 301 de la Gobernación de la Guajira, por 
medio del cual se realizó una evaluación social y un plan de pueblos indígenas, las fuentes de abastecimiento de agua de la comunidad wayúu que han perdurado por años y forman parte de sus tradiciones ancestrales son: las casimbas, los jagüeyes, los molinos eólicos, las aguas lluvias, los carrotanques, los pozos profundos y los ojos de agua salada. En los siguientes párrafos se describen algunas de estas fuentes de abastecimiento, por su carácter inusitado.

Los jagüeyes son reservorios hechos en tierra, constituyen la principal fuente de abastecimiento de los indígenas wayúus que habitan en la zona rural de la Guajira. En la mayoría de los casos el agua que se recoge en estos sistemas de almacenamiento es consumida por las personas sin ningún tratamiento previo, lo que propicia situaciones de alto riesgo para la salud humana, particularmente en la población infantil (Revista Mundo Cerrejón, 2010, (59), 9).

Las casimbas, según el antropólogo Benson Saler, son depresiones abiertas y se ubican con frecuencia en depresiones que se llenan con agua lluvia. Constituyen una de las formas de abastecimiento de agua más comunes dentro de la comunidad wayúu.

Los pozos: son agujeros, excavaciones o túneles verticales que perforan la tierra, hasta una profundidad suficiente para alcanzar lo que se busca, en el caso de las comunidades wayúus una reserva de agua subterránea.

Las albercas: son construcciones hidráulicas, bien excavadas en tierra, bien realizadas, con fábrica de ladrillo, tapial o mampostería, en forma de estanque, para almacenar agua.

Molinos eólicos: utilizados con bombas eólicas de agua como un mecanismo de bombeo que funciona accionado por la fuerza del viento. En general, son utilizados a pequeña escala para abastecer de agua potable. 


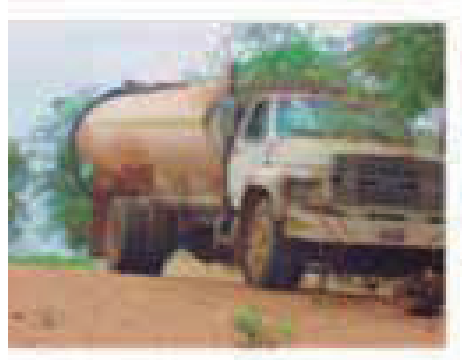

Carro

tanque

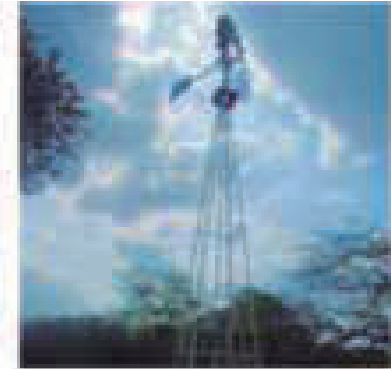

Molinos eólicos

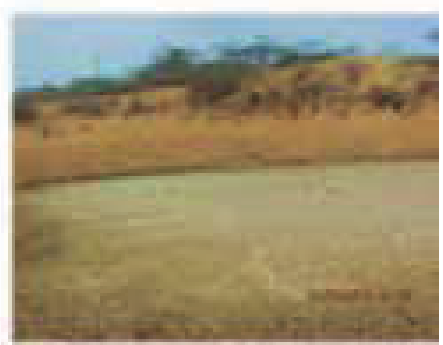

Jagüeyes

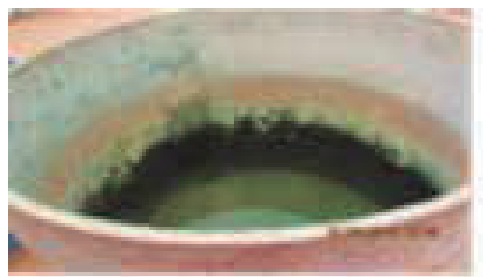

Casimbas
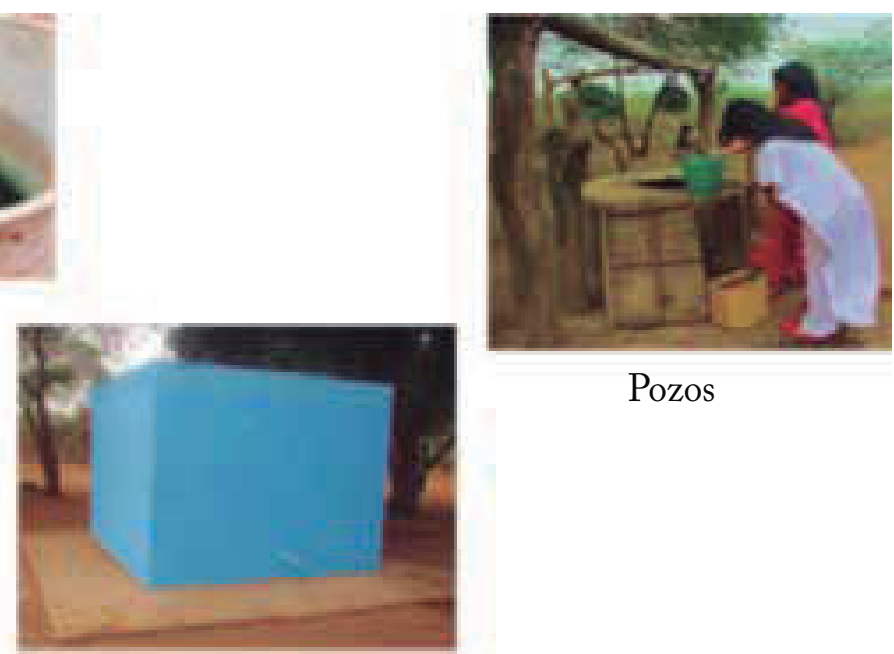

Pozos

Albercas

Figura 1. Fuentes de abastecimiento de agua de la comunidad wayúu

Fuente: Proyecto de investigación Derecho humano al agua en la comunidad wayúu bajo la figura matrilineal (2014)

\section{Planes y políticas públicas con respecto al derecho humano} al agua en el departamento de la Guajira, Colombia

Con el fin de garantizar y ejecutar el derecho humano al agua en el departamento de la Guajira, a lo largo del tiempo se han desarrollado diferentes planes para que, de conformidad con la ley y las necesidades de la población, este recurso se utilice de la mejor manera posible. A continuación algunos ejemplos. 


\section{Plan departamental para el manejo empresarial} de los servicios de agua y saneamiento (2010)

Elaborado por el Ministerio de Ambiente, Vivienda y Desarrollo Territorial, este plan se fijó el propósito de poner el tema de agua en la agenda pública nacional y local. El problema de falta de agua potable y la ausencia de saneamiento básico en miles de hogares colombianos no podía seguir siendo ignorado y tampoco podía ser abordado exclusivamente desde el campo de los servicios públicos. La situación tenía que ser abordada como lo que era: un problema de dignidad humana, habida cuenta que más de setecientos municipios pequeños y medianos, más de doce millones de colombianos, requerían una respuesta real a sus necesidades.

Con este horizonte, por cerca de ocho años, el equipo humano de la antigua Dirección de Agua Potable y Saneamiento Básico, hoy Viceministerio de Agua y Saneamiento, trabajó para elaborar, producir e implementar una política pública que transformara al sector definitivamente. A este fin se estructuró la política de Planes Departamentales de Agua Potable y Saneamiento Básico, como un grupo de estrategias presupuestales, fiscales y técnicas que, coordinadas por los departamentos, permitieran planificar adecuadamente la implementación de este recurso en pro de los servicios públicos de acueducto y alcantarillado.

A la fecha se ha podido desarrollar un proceso de diagnósticos de la situación de los municipios con relación a la prestación de los servicios de acueducto, alcantarillado y aseo. De esta manera, las inversiones programadas y la ejecución de obras físicas del Plan obedecen al análisis de las necesidades reales de la población afectada, promoviéndose así la eficiencia en la aplicación de los recursos aportados. 


\section{Diagnósticos sectoriales del departamento de la Guajira}

Se realizaron y se concertaron en su totalidad los diagnósticos de los servicios de acueducto y alcantarillado y su componente ambiental e institucional. Esta actividad, que se llevó a cabo en los años 2004 y 2005, implicó que se valoraran necesidades de inversión en todos los municipios, con base en planes maestros existentes y en la información suministrada por los entes territoriales. Teniendo en cuenta esta información, se fijaron metas de cobertura de acueducto y alcantarillado urbano que se plasmaron en el Documento Conpes 3430 del 2006, conciliando los diferentes diagnósticos realizados por la firma Equity, la gerencia estructuradora en el 2007 y los entregados por los operadores y la Gobernación en el 2008. E1 24 de septiembre de ese año se elaboró y firmó el acta de concertación del diagnóstico. En materia de acueducto, el departamento presenta una cobertura del 72\% y en alcantarillado el $46 \%$ (Gobernación de La Guajira y Operadores, citado Conpes 3430 del 2006).

\section{Evaluación Social y Plan de Pueblos Indígenas para el} proyecto Construcción y sostenibilidad de once (11) reservorios y un (1) micro acueducto, en comunidades Indígenas de la alta Guajira (Gobernación de la Guajira, 2011)

La Guajira alberga uno de los resguardos indígenas más grandes del país, el de la Alta y Media Guajira, perteneciente a la etnia wayúu, con una extensión de 1'067505 hectáreas y una población de 121469 habitantes. Comprende la totalidad de los municipios de Uribía y Manaure y parte de los municipios de Riohacha y Maicao. La Gobernación de la Guajira se propone ubicar geográficamente once proyectos de reservorios y un acueducto para mejorar la distribución y el correcto uso y repartición del recurso agua. 
Fragmento de la entrevista realizada al subdirector de gestión ambiental Samuel Santander Lanao Robles en las instalaciones de Corpoguajira

Fecha: 02/05/2014

E: entrevistador

S: subdirector

\section{E: ¿Cuáles son las funciones de Corpoguajira con respecto al tema hídrico?}

S: La Corporación Autónoma Regional de la Guajira tiene legalmente la competencia de la administración de recursos hídricos en el departamento de la Guajira. Además, la Ley 99 le da a la Corporación la competencia para la provisión de agua a las comunidades indígenas y afrodescendientes dentro de su jurisdicción.

\section{E: ¿Cuál es el papel de Corpoguajira frente al desarrollo} de las políticas públicas con base en el agua?

S: Las políticas públicas se reflejan en la normatividad colombiana en relación con el recurso hídrico, ahí existe una competencia como por parte nuestra de administrar el recurso hídrico en todo el departamento. Adicionalmente a esto, la provisión de agua a la comunidades indígenas y afrodescendientes, nosotros implementamos programas y proyectos para atender ese mandato legal, es así como históricamente la Corporación ha hecho presencia en los municipios del departamento de la Guajira, especialmente en la comunidad indígena wayúu, en las comunidades indígenas asentadas en la Sierra Nevada de Santa Marta, llevando el suministro de agua y complementando la acción, recalcando que quien tiene la competencia directa para la prestación de servicio de agua potable a las comunidades del departamento de la Guajira son 
las alcaldías municipales, a través de la Ley 142 de Servicios Públicos, pero nosotros tenemos una función complementaria por el ordenamiento legal, y eso lo estamos realizando.

\section{E: ¿Cómo ayuda la Corporación a garantizar el derecho humano al agua en las comunidades wayúus?}

S: A través de la provisión de agua, de la construcción de sistemas de abastecimiento. Hay que recalcar que debido a la dispersión de las comunidades indígenas en el territorio, es difícil llevar solución agua, pero lo hemos venido haciendo con los diferentes sistemas no convencionales; por ejemplo, la construcción de pozos profundos, de jagüeyes, llevar agua a través de los carrotanques, y de esa manera hemos logrado penetrar y cumplir con ese ordenamiento normativo.

\section{E: La Corporación a través de la relación con las comunidades wayúus, ¿cuál considera, a través} de su experiencia, que es el papel de las mujeres y las niñas en todo el proceso de abastecimiento?

S: Por cultura, podemos observar que la mujer tiene un papel preponderante en la cultura wayúu. Vemos que es quien va a buscar el agua. Por la dispersión los sistemas no pueden ser tan puntuales, ubicados en sitios donde se centraliza la población. En muchos casos las comunidades tienen que recorrer muchos kilómetros, de cinco a diez, para buscar el agua, y allí la mujer desempeña ese papel importante, debido a que es ella quien va y busca el agua para poder suministrar a sus comunidades, a su gente y su familia. Eso hay que resaltarlo en la mujer guajira, ese liderazgo y esa capacidad de servicio que tiene con su comunidad. 


\section{E: ¿Qué proyectos ha llevado a cabo la Corporación?}

La Corporación desde su existencia, que lleva ya treinta años, ha hecho presencia y ha mantenido un liderazgo en la provisión de agua a las comunidades indígenas, y son muchos los proyectos. Podríamos darle el listado, ya que no podría enumerarlos, porque se gastaría todo el tiempo para suministrar esa información, pero podemos darle un listado de todas las acciones que hemos venido realizando con la construcción de pozos profundos, jagüeyes, suministro de agua a través de carrotanques, sistemas de potabilización de agua salobre, construcción de albercas. Todo el esfuerzo que ha sido necesario hacer para provisión de agua a las comunidades, y tenemos las evidencias para demostrar que de esa manera se ha realizado.

\section{El papel de las mujeres y niñas wayúus en el abastecimiento de agua}

Se da respuesta a esta pregunta a través de un grupo focal en La Ranchería "Campamento”, con la participación de un grupo de doce mujeres (quienes reservaron su identidad) de la ranchería anteriormente mencionada (fragmento de las intervenciones: $\mathrm{M}$ : mediador P: participantes).

\section{M: ¿Cuál es el rol de las mujeres y niñas wayúus en el abastecimiento de agua?}

P: Es un derecho que se adquirió en el 2010, pero nosotros estamos en una comunidad muy pobre de agua, aquí no hay agua por ninguna parte, ni un río ni nada, entonces es muy difícil el agua, solo hay unos molinos, y ¿̇a quién le toca?... a la mujer. El trayecto es muy largo para conseguir el agua, y para las niñas, así que en esta comunidad carecemos de agua. 
M: ¿Y eso afecta que las niñas vayan a la escuela por ayudar en su casa?

P: claro, porque esta es una comunidad donde primordialmente los niños wayúus tienen que ayudar en la casa, y más la niña, ella es la que sale y busca el agua, porque eso es algo de la cultura, entonces muchas veces como no hay agua, vienen sin bañarse.

\section{M: ¿Cómo es el proceso de recolección de agua?}

P: Este proceso se hace diariamente, todas las tardes, pero por la necesidad, la recolección siempre se hace en las horas de la mañana, o en la tarde para evitar la cuestión del sol o el cansancio. El método de buscar el agua es en burro o en carreta, la distancia depende del lugar donde se vaya a buscar, dos o tres horas. Diariamente hay cuatro desplazamientos y esta actividad está a cargo de las mujeres o niñas, máximo están echando unos ochenta litros en cada viaje, porque hay un burro que le ponen los tanques, acá hay pozo, hay un jagüey, pero le falta mantenimiento y ahora mismo está totalmente seco, hay deficiencia con los tanques porque no tienen mucha limpieza y no es bueno tomar de ahí, da fiebre y enfermedades. De estas enfermedades se encargarían las madres, por su medicina tradicional, ellas mismas hacen sus recetas y esas cuestiones, a parte a ellas se les hace difícil trasladarse al hospital por la lejanía.

\section{M: ¿Cómo afecta la vulneración del derecho humano}

al agua a otros derechos humanos en las wayúus?

P: Sí son vulnerados otros derechos, porque a veces nos pasa que algunas niñas no vienen a clase porque les toca arriar agua, o sea ir en burro, hacer varios viajes todo el día y es una distancia bastante larga, se pasan todo el día arriando agua. Las mamás 
de las niñas dicen que primero es el agua, porque la utilizan para cocinar, lavar, bañarse, para todos los oficios, e igualmente algunas niñas vienen y dicen que no les dio tiempo para hacer la tarea, porque llegan del colegio y no hay agua para cocinar y les toca arriar agua toda la tarde hasta la noche, $y$ al día siguiente llegan sin hacer las tareas, y así sucede en muchas partes de aquí. Algunas personas son conscientes y les permiten a sus hijos jugar un rato, pero hay unos que no, apenas llegan tienen que arriar el agua, y es porque algunas madres piensan que el oficio de las niñas es ese, arriar el agua.

\section{Concepto de agua para las mujeres y niñas wayúus}

"Primeramente, el concepto de agua para la comunidad indígena, wayúu, es que el agua es vida; sin agua no podemos vivir y el wayúu no puede vivir sin agua, sobre todo la agricultura, para el sustento diario, para todos los quehaceres necesitamos agua, la falta de agua afecta de todas maneras, porque si en la casa no hay agua las niñas no acuden al colegio, porque no se han bañado, no tienen para cocinar los alimentos, entonces como ellos tienen que buscar el agua de un lugar tan distante, se les dificulta venir a clase, cumplir con sus labores académicas. Por ese motivo, porque es distante buscar el poquito de agua, porque ellos no tienen tampoco unas condiciones adecuadas, por lo menos una alberca, un tanque grande en el que puedan almacenar su agua y entonces es difícil, ellos únicamente traen como unas pimpinas que decimos aquí en la Guajira y es muy difícil para ellos traer esa agua que es para el sustento diario.

En la parte cultural el agua es juya, cuando en la época del invierno, juya viene a aquí a la tierra, entonces juya moja la tierra y el wayúu se alegra porque ya sus cultivos van a producir para su alimentación, entonces es muy importante porque juya 
venga juya es la lluvia a visitar la tierra porque de ahí es todo, los animales" (Mujer wayúu. Identidad reservada).

\section{Acciones de las mujeres wayúus para hacer valer el derecho humano al agua}

La mujer hace valer esos derechos, porque es ella haciendo la gestión en la comunidad. Más que todo gestiona la líder, hacia la alcaldía que presta ese servicio para hacer llegar el agua. No todas las comunidades pueden, ya que hay algunas que están alejadas, entonces las que tienen líder, esta gestiona el trayecto del agua desde donde está hacia la comunidad, para que así puedan beneficiarse los que están alrededor de la comunidad. También lo gestiona a través de la política, tiene que agarrarse de un político para que la puedan llegar a apoyar, porque a veces cuando la líder no está, el agua no llega.

Surge la pregunta sobre por qué una mujer líder en estas comunidades, esto debido a que en la cultura wayúu prevalece la línea materna, la mujer es más importante que el hombre, por lo que toma las decisiones, alegando la capacidad de tener hijos. Por eso es que se dice que la mujer wayúu es símbolo de respeto; por ejemplo, hay mujeres que arrían el agua, recogen la leña, arrían los chivos. En conclusión, es un rol muy importante el que tiene la mujer.

\section{Conclusiones}

Este documento contiene los avances y resultados que se lograron durante la investigación. Por esta razón, las siguientes conclusiones pretenden dar respuesta al problema planteado en la investigación y describir la trascendencia del trabajo investigativo.

Así como en los artículos $3^{\circ}$ y $4^{\circ}$ de la Declaración de las Naciones Unidas sobre los derechos de los pueblos indígenas, 
estos tienen derecho a la libre determinación, también debe tenerse en cuenta el artículo $1^{\circ}$, el cual consagra que los indígenas tienen derecho, como pueblos o como individuos, al disfrute pleno de todos los derechos humanos y las libertades fundamentales reconocidas en la Carta de las Naciones Unidas, la Declaración Universal de Derechos Humanos y las normas internacionales de derechos humanos.

En este mismo sentido, se destacan dos pronunciamientos principales sobre el derecho humano al agua: la Observación General no 15, adoptada por el Comité de Derechos Económicos, Sociales y Culturales en el 2002, y la Resolución 64/292 de la Asamblea General de las Naciones Unidas, reconocida el 28 de julio del 2010. En nuestro país, la Corte Constitucional también se ha pronunciado afirmando que el derecho de toda persona al agua es un derecho fundamental. Pero ante las condiciones ambientales de la Guajira y la escasez de agua podemos concluir que esta situación va en contra de todos los pronunciamientos anteriormente mencionados.

El derecho humano al agua es fundamental e indispensable para concretar otros derechos humanos y/o fundamentales, como lo es el derecho a la salud, y por ende el derecho a la vida, ya que estos no se pueden definir sin un acceso a sistemas de agua potable limpia y al saneamiento.

La escasez de sistemas adecuados de abastecimiento de agua y saneamiento afecta la realización de los demás derechos humanos a las mujeres y niñas wayúus, debido a que obliga a que tengan que realizar largas travesías en busca de recursos hídricos, invirtiendo considerable tiempo y fuerza laboral diariamente, alejándose de un gran número de actividades participativas, lo que supone una desventaja con respecto a los hombres de la comunidad. Es por esto que podemos afirmar 
que a las mujeres y niñas wayúus no se les garantiza el derecho humano al agua.

En cuanto a las políticas públicas propuestas en el departamento de la Guajira para solucionar todos los problemas que acarrea la vulneración del derecho humano al agua, podemos observar que no son más que solo eso: "propuestas", pues los resultados son escasos y muchas veces imperceptibles. Nuevamente, inferimos que no hay garantía por parte del Estado de este derecho, ello sin mencionar que otros problemas, como consecuencia de la falta de agua potable y saneamiento, aún no han sido tocados por el Gobierno. Es el caso del impacto que tiene, desde la perspectiva matrilineal, el desabastecimiento de este preciado líquido, un tema muy valioso que considerar como objeto de debate y para asistir a las mujeres y niñas wayúus en los padecimientos que sufren como consecuencia de la vulneración del derecho humano al agua.

\section{La infinitud}

Talhua, alaüla de Toolünare, nos ha contado que también provenimos de otros mundos... que acumulamos un saber antiguo creador de otros llantos, de otros sueños, de otros pasos... que nuestra sonrisa se extiende en otros labios más allá de esta orilla de la mar. Como nuestra sangre hay un río invisible que nos recorre a todos $[. .$.$] donde viajan$ la misma risa y el mismo silencio. Vito Apushana (2010) 


\section{Referencias}

Apud, A. (2013). Las mujeres y el agua. España: Dirección de Comunicación de Unicef.

Apushana, V.(2010). En las hondonadas maternas de la piel. Bogotá: Ministerio de Cultura.

Bautista,J.(2013). El derecho humano al agua y al saneamiento frente a los Objetivos de Desarrollo del Milenio. Naciones Unidas/ Cepal. Recuperado de http://www.ohchr.org/Documents/ Issues/Water/ContributionsSustainability/ECLAC7.pdf.

Colombia, Congreso de la República (1994). Ley 142 de 1994, que establece el régimen de los servicios públicos domiciliarios. Recuperado de http://www.secretariasenado.gov.co/senado/ basedoc/ley/1994/ ley_0142_1994.html

Comité de Derechos Económicos Sociales y Culturales (cDEsc) (2002). Observación General no 15, El derecho al agua (articulos 11 y 12 del Pacto Internacional de Derechos Económicos, Sociales y Culturales). Recuperado de http://www.rlc.FAo. org/frente/pdf/og15.pdf

Corte Constitucional Colombiana (2007). Sentencia T-270. Magistrado ponente: Jaime Araujo Rentería.

Hernández, R., Fernández, C. y Baptista, P. (2006). Metodología de la investigación. México: McGraw-Hill.

Instituto Interamericano de Derechos Humanos (2006). El módulo Agua, pueblos indigenas, y derechos humanos. Recuperado de http://www.bvsde.paho.org/bvsapi/e/proyectreg2/paises/costarica/agua.pdf)

Ledo, M.C. (2005). Agua potable a nivel de hogares con una dimensión de género: derecho de las mujeres al agua en las ciudades de El Alto, La Paz y Cochabamba. Cochabamba: Ceplag.

Molinares, V.y Echeverría,J. (2011). El derecho humano al agua: Posibilidades desde una perspectiva de género. International 
Law, (19),269-301. Recuperado de http:/www.scielo.org.co/ scielo.php?script=sci_arttext\&pid=S169281562011000200 009\&lng=en\&tlng=es

Ojeda, G. (2011). La mujer wayuu. Recuperado de http://www. achijirawaa.co/node/652

Ordeñana, T. (2000). Los derechos de las mujeres son derechos humanos. Revista Jurídica. Facultad de Derecho de la Universidad Católica de Guayaquil. Recuperado de http://www. revistajuridicaonline.com/index.php?option=com_content \&task=view\&id=94\&Itemid=39

Organización de las Naciones Unidas, Asamblea General (2010). Resolución A/64/L.63/Rev.1. Recuperado de http://daccess-dds ny.un.org/doc/undoc/LTD/N10/464/67/PDF/ N1046467.pdf?OpenElement

Organización de las Naciones Unidas (2011). El agua más preciada de las mujeres wayuu. Recuperado de http://www.un.org/ content/es/_vidout/video5.shtml

Pulgarín, C. (1997). La mujer wayuu. El Tiempo. Recuperado de http://www.eltiempo.com/archivo/documento/MAM577970

Quigua, A. (2011). Derecho al agua-Jurisprudencia Constitucional en Colombia. Bogotá: Polo Democrático Alternativo.

Ramírez, G. et al. (2009). Diagnóstico del cumplimiento del derecho bumano al agua en Colombia. Bogotá: Defensoría del Pueblo. Tamayo, M. (2003). Metodología formal de la investigación cientifica. Bogotá: Comes. 